\title{
The importance of solid employment for health
}

There is ample evidence that labor-force participation is an important determinant of health inequalities, as demonstrated by higher morbidity and mortality among unemployed persons (1-3). The association between health and employment is bi-directional in that poor health may increase the probability of becoming unemployed (selection hypothesis) and unemployment may cause poor health (causation hypothesis). The selection mechanism has been demonstrated in various studies in occupational health. In a Finnish cohort of men, self-assessed poor health was a strong predictor of both disability and nonillness-based early retirement (4). In most European countries, poor health or a chronic health problem predicts staying or becoming unemployed, and the effects of health are stronger with a lower national unemployment level (5).

The causation mechanism has received less attention in occupational health but certainly deserves unequivocal attention. A longitudinal study with a 10-year follow-up showed that unemployment had a strong effect on the incidence of any limiting illness and that employment was also related to recovery from these illnesses (6). Loss of employment has typically been associated with negative effects on mental health $(7,8)$, and gaining employment has been shown to improve mental health (7).

The aforementioned studies have focused on employment per se, but recent studies have pointed out that health inequalities also exist among employed persons across different types of employment. A recent review provided evidence for a relationship between temporary employment and increased psychological morbidity, possibly reflecting the adverse effects of job insecurity on mental health (9).

Given the importance of type of employment for population health, it is of interest to know what proportion of worklife is spent in temporary employment. In this issue of the Scandinavian Journal of Work, Environment \& Health, Nurminen has estimated that, in 2006, a Finnish man was expected to work a total of 3.8 years under a fixed-term employment contract, which was approximately $8 \%$ of his remaining work career from the time of entry until final retirement. Finnish women were expected to work an average of 6.5 years or $13 \%$ in fixed-term employment. Over the past decade, the ratio of women to men in fixed-term employment increased consistently from 1.4 to 1.7 (10). This gender effect is surprising in a country with a traditionally high labor-force participation among women, which is almost equal to the labor-force participation of men.

For full appreciation of these findings, some characteristics of the study have to be considered in detail. First, worklife expectancy was estimated for permanent versus fixed-term employment, and selfemployed persons (who ended up in a single category together with students, unemployed persons, persons with a disability pension, and early retirees) were thereby excluded. In 2006, the proportion of self-employed persons was approximately twice as high among men as among women in Finland, and, therefore, a gender-differential shift from fixed-term employment to self-employment may have biased the results to some extent. Second, the method of assessment was based on sequential cross-sectional survey data, and, as a consequence, it estimated the total duration of being in a specific type of employment. As stated by the author, this approach has limited discriminatory power for some types of employment being included in the analysis. It would certainly be of interest to extend the current study with a longitudinal approach, with records at the individual level, in order to distinguish between several other types of employment, including self-employment and part-time employment, and to evaluate which factors determine transitions among different types of employment and unemployment.

What are the new insights and consequences of the reported trends for fixed-term employment in Finland? The study by Nurminen shows that workers spend a substantial part of their worklife in fixed- 
term contracts, especially while they are young. This situation can be regarded as the natural course of worklife, to start in fixed-term jobs before moving into permanent positions. However, women's longer employment in these fixed-term jobs and the growing divergence between women and men in the past decade are worrying observations. Since job insecurity may have adverse health effects, the increase in worklife expectancy in fixed-term contracts among women and not among men will increase the health inequalities between women and men.

The interrelationship between health and type of employment is an important area for research since the mechanisms through which different types of nonpermanent employment influence health are only partly understood. There is emerging evidence that temporary jobs are associated with more hazardous work conditions, but evidence of this phenomenon's contribution to the pathway from temporary employment to ill health remains scarce $(9,11)$. There may be a vicious cycle in which persons with less than good health are more likely to end up in nonpermanent jobs with a less favorable social and physical environment, and, subsequently, experience adverse health outcomes. This accumulation of problems with health and employment can lead to a further deterioration of health status and to long-term unemployment and may particularly be concentrated in groups already disadvantageous in other areas, such as education and social conditions.

An important question is what society should do with unhealthy job seekers, unhealthy workers, and unhealthy jobs. III health is an important barrier for getting and maintaining paid employment, and workers in fixed-term employment may be less well off than workers in permanent employment. Given the profound impact of work-related ill health on the socioeconomic position of individuals, occupational health researchers and practitioners should investigate how people with poorer health can be facilitated to enter or stay engaged in the labor market (12). Occupational health should actively pursue a position in the public debate on the expanding costs of social security in an aging society, since timely interventions at the workplace and on type of employment contract can contribute to increased labor-force participation among all workers.

\section{References}

1. Janlert U. Unemployment as a disease and diseases of the unemployed. Scand J Work Environ Health. 1997;23 suppl 3:7983

2. Morris JK, Cook DG, Shaper AG. Loss of employment and mortality. BMJ. 1994;308:1135-9.

3. Ho JJ, Hwang JS, Wang JD. Life-expectancy estimations and the determinants of survival after 15 years of follow-up for 81249 workers with permanent occupational disabilities. Scand J Work Environ Health. 2006;32(2):91-8.

4. Karpansalo M, Manninen P, Kauhanen J, Lakka TA, Salonen JT. Perceived health as a predictor of early retirement. Scand J Work Environ Health. 2004;30(4):287-92.

5. Schuring M, Burdorf A, Kunst A, Mackenbach J. The effects of ill health on entering and maintaining paid employment: evidence in European countries. J Epidemiol Community Health. 2007;61:597-604.

6. Bartley M, Sacker A, Clarke P. Employment status, employment conditions, and limiting illness: prospective evidence from the British household panel survey 1991-2001. J Epidemiol Community Health. 2004;58:501-6.

7. Murphy GC, Athanasou JA. The effect of unemployment on mental health. J Occup Organ Psychol. 1999;72:83-99.

8. Honkonen T, Virtanen M, Ahola K, Kivimäki M, Pirkola S, Isometsä E, et al. Employment status, mental disorders and service use in the working age population. Scand J Work Environ Health. 2007;33(1):29-36.

9. Virtanen M, Kivimäki M, Joensuu M, Virtanen P, Elovainio M, Vahtera J. Temporary employment and health: a review. Int J Edpidemiol. 2005;34:610-22.

10. Nurminen M. Working life expectancies of fixed-term employees in Finland 1997-2006. Scand J Work Environ Healt. In press.

11. Benach J, Benavides FG, Platt S, Diez-Roux A, Muntaner C. The health-damaging potential of new types of flexible employment: a challenge for public health researchers. Am J Public Health. 2000;90:1316-7.

12. Burdorf A. Economic evaluation in occupational health—its goals, challenges, and opportunities [editorial]. Scand J Work Environ Health. 2007;33(3):161-4.

Scandinavian Journal of Work, Environment \& Health

Alex Burdorf, Associate Editor

[E-mail: a.burdorf@erasmusmc.nl] 